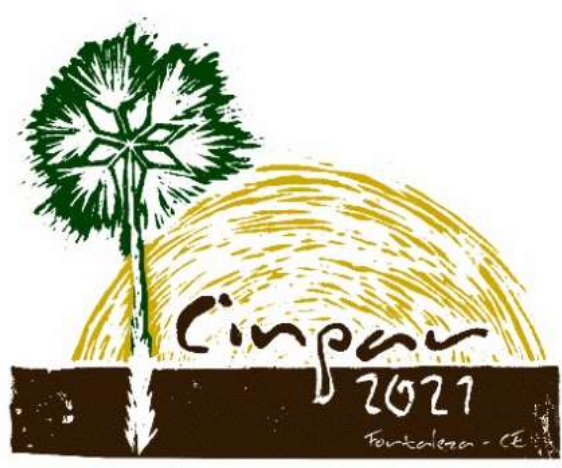

XVII Congresso Internacional sobre Patologia e Reabilitação das Construções

XVII Congreso Internacional sobre Patología y Rehabilitación de las Construcciones

XVII International Conference on Pathology and Constructions Rehabilitation

FORTALEZA (Brasil), 3 a 5 de junho de 2021

https://doi.org/10.4322/CINPAR.2021.070

\title{
Assistência Técnica e Manutenção de Condomínios Verticais no município de João Pessoa-PB
}

\section{Technical Assistance and Maintenance of Vertical Condominiums in the municipality of João Pessoa-PB}

\author{
Cibelle Guimarães Silva SEVERO ${ }^{1}$, João Antônio Honorato CARVALHO², \\ ${ }^{1}$ UFPB, João Pessoa-PB, Brasil, cibelleguimaraes@yahoo.com.br 1 \\ ${ }^{2}$ UFPB, João Pessoa-PB, Brasil, jahonoratoc@gmail.com 2
}

\begin{abstract}
Resumo: O acompanhamento de uma edificação deve continuar em toda sua vida útil. Segundo o código civil brasileiro, os responsáveis técnicos pela construção respondem pela sua solidez e segurança nos primeiros cinco anos de vida. Dessa forma, a construtora deve fornecer suporte técnico ao edifício, sendo responsabilizada pelos vícios e defeitos construtivos no período. Em paralelo, os administradores do condomínio devem executar os serviços de manutenção previstos no manual de uso, operação e manutenção, elaborado e entregue pela construtora, para garantir que a edificação mantenha níveis de desempenho aceitáveis durante sua vida útil. Este trabalho, objetiva avaliar o programa de assistência técnica das construtoras à condomínios verticais do município de João Pessoa nos primeiros cinco anos de vida. $\mathrm{A}$ amostra foi selecionada, com base em critérios que descrevem o padrão econômico médio das edificações mais recentes do município (com menos de cinco anos de vida). Em seguida, foi elaborado um questionário direcionado aos síndicos e empresas administradoras de condomínio. O objetivo do questionário foi coletar informações sobre as manifestações patológicas mais comuns, sobre as principais percepções relacionadas ao suporte técnico dado pelas construtoras e a atuação dos responsáveis pela administração dos condomínios da amostra. Os resultados do estudo mostraram que o suporte aos edifícios é preterido por algumas construtoras, sendo visto como algo secundário pelas empresas. Além disso, a atuação dos administradores dos edifícios, principalmente com relação às ações de manutenção, está aquém das necessidades do condomínio.
\end{abstract}

Palavras-Chave: Manifestação patológica; Manual do Proprietário; Desempenho; Pós-obra.

\begin{abstract}
The monitoring of a building should continue throughout its useful life. According to the Brazilian civil code, the technical leaders for the construction are responsible for their solidity and safety in the first five years of life. Thus, the construction company must provide technical support to the building, being responsible for defects and construction defects in the period. In parallel, condominium administrators must perform the maintenance services provided for in the manual of use, operation and maintenance, prepared and delivered by the construction company, to ensure that the building maintains acceptable performance levels during its useful life. This work aims to evaluate the technical assistance program of construction companies to vertical condominiums in the municipality of João Pessoa in the first five years of life. The sample was selected, based on criteria that describe the average economic pattern of the most recent buildings in the municipality (with less than five years of life). Then, a questionnaire was prepared to the liquidators and condominium management companies. The objective of the questionnaire was to collect information about the most common pathological manifestations, about the main perceptions related to the
\end{abstract}


technical support given by the construction companies and the actions of those responsible for the administration of the condominiums of the sample. The results of the study showed that the support to buildings is deprethetised by some construction companies, being seen as something secondary by companies. In addition, the performance of the building administrators, especially in relation to maintenance actions, falls short of the needs of the condominium.

Keywords: Pathological manifestation; Owner's Manual; Performance; Post-work

\section{Introdução}

O mercado da construção civil passou por fases de crescimento e recessão, de acordo com a situação econômica do país. Do Plano de Metas, no governo de Juscelino Kubitschek, passando pelo "milagre econômico" durante o Regime Militar e, mais recentemente, com o Programa de Aceleração do Crescimento (PAC) e o Minha Casa, Minha Vida (MCMV), o Brasil viveu os ápices da engenharia civil.

Nos momentos positivos mais recentes da indústria, fatores como a facilidade de crédito para construir e a necessidade de grandes obras financiadas pelo governo impulsionaram ainda mais o mercado. A criação do PAC em 2007 e do MCMV em 2009, aqueceram e fomentaram o desenvolvimento dos setores público e privado da construção civil na última década. Entre 2008 e 2015, o investimento na indústria foi superado mais que o dobro, de 159 bilhões para mais de 331 bilhões de reais (JESUS, ANJOS, et al., 2018).

Porém, tal crescimento da indústria da construção veio acompanhado de problemas. No setor privado, a busca por baratear as obras para ampliar o lucro, o crescimento de obras gerenciadas sem profissional habilitado, aliado a um mercado que absorvia produtos de baixa qualidade, fizeram com que a qualidade das construções caíssem. Já no setor público, os escândalos de corrupção evidenciaram grandes obras de custo elevado e de baixa qualidade, fruto do superfaturamento de materiais e mão-de-obra.

A crescente aparição de danos estéticos e estruturais decorrentes de falhas na fase de projetos, de erros durante a execução, da escolha inadequada de materiais e da precipitação dos construtores por um resultado nas mãos do cliente de forma antecipada evidenciam a importância de estudar sobre as manifestações patológicas. Identificar suas causas, apontando responsabilidades e aplicando as técnicas mais adequadas para posteriores reparos é o melhor caminho no seu tratamento.

Mesmo após a entrega da edificação já pronta, os cuidados com o aparecimento de vícios e defeitos devem ser mantidos. O desempenho do edifício e de seus sistemas só será satisfatório mediante manutenções periódicas, de responsabilidade do síndico, dos proprietários e/ou da empresa especializada contratada pelo condomínio. Os procedimentos para manutenção devem estar descritos no Manual de Uso, Operação e Manutenção, elaborado pela construtora ou incorporadora responsável. (ASSOCIAÇÃO BRASILEIRA DE NORMAS TÉCNICAS, 2013).

São comuns os casos de aparecimento de manifestações patológicas devido a falta de um programa adequado de manutenção. A ausência de processos de manutenção preventiva pode comprometer a saúde e a segurança dos usuários das edificações, além de prejuízos financeiros ao condomínio com gastos não previstos para reparar os danos e com a desvalorização do imóvel.

De acordo com o Código de Defesa do Consumidor (CDC), as construtoras oferecem um prazo de garantia legal mínimo de 5 anos após a expedição do habite-se contra vícios ocultos. Os vícios são falhas que tornam 
o imóvel impróprio para o uso ou diminuem o seu valor. Sendo ocultos, são de difícil constatação imediata e costumam aparecer depois de certo tempo passado. (INSTITUTO BRASILEIRO DE AVALIAÇÕES E PERÍCIAS DE ENGENHARIA, 2015).

Realizar manutenções nos prazos previstos pelo Manual é requisito para manter a garantia legal da edificação, garantindo o suporte da construtora durante os cinco anos. O programa sugerido no Manual deve ser constantemente atualizado, acompanhando as mudanças realizadas no condomínio.

O presente trabalho visa analisar uma amostragem de edifícios residenciais dentro da garantia legal (ou seja, com menos de cinco anos de vida) em João Pessoa, construídos por empresas diferentes, para avaliar o suporte das construtoras/incorporadoras nos primeiros anos de vida e verificar se o programa de manutenção sugerido no Manual de Uso, Operação e Manutenção está sendo seguido e atualizado pelos responsáveis pela gestão do condomínio.

Outro foco do trabalho é analisar a conformidade dos Manuais do Proprietário dos edifícios estudados com base na ABNT NBR 14037:2014. A norma dita o que deve ser informado aos proprietários do imóvel para preservar as condições de uso durante a vida útil da edificação, apresentando informações técnicas necessárias ao desenvolvimento das atividades de uso, operação e manutenção dos imóveis. (ASSOCIAÇÃO BRASILEIRA DE NORMAS TÉCNICAS, 2014)

\section{Metodologia}

Este trabalho segue como metodologia uma pesquisa de levantamento, com aplicação de um questionário voltado aos síndicos e empresas administradoras de condomínios. O objetivo do questionário é avaliar a atuação da empresa construtora/incorporadora com base nas respostas dos responsáveis pela administração dos edifícios da amostra.

A abordagem utilizada no questionário possui elementos quantitativos e qualitativos, com perguntas objetivas e discursivas. A pesquisa é do tipo exploratória, pois objetiva caracterizar o suporte das construtoras e a atuação dos síndicos e empresas especializadas por meio do questionário e da análise do Manual do Proprietário com base na NBR 14037.

O questionário foi aplicado on-line, por meio da plataforma Google Docs. As respostas do questionário foram obtidas entre dezembro de 2019 e fevereiro de 2020.

Para o presente trabalho, foi utilizada uma amostra com 5 edifícios, de médio padrão, contemplados pelas seguintes características: Menos de $100 \mathrm{~m}^{2}$ por apartamento; Área de lazer comum (piscina, salão de festas, playground etc.); Menos de 5 anos de vida até o momento da pesquisa; Mais de 15 pavimentos; Construído por construtoras diferentes.

Os edifícios da amostra vão de 20 a 34 pavimentos, entre 60 e 240 apartamentos em cada. 0 prédio mais novo está com 9 meses de funcionamento, contados até março de 2020; já o mais antigo, 3 anos e 8 meses. 


\section{Resultados}

\subsection{Vícios Construtivos}

Em todos os edifícios analisados foram realizadas vistorias de entrega, tanto nos apartamentos quanto nas áreas comuns. Segundo os síndicos e administradores dos condomínios, foram encontradas falhas e defeitos aparentes em $80 \%$ dos edifícios.

Nos apartamentos, os problemas encontrados no ato da entrega foram: Falhas na colocação dos revestimentos cerâmicos de piso e parede (erros no caimento do piso para os ralos, falhas no rejuntes); Problemas nas esquadrias (portas e janelas abrindo com dificuldade, danos estéticos) e; Falhas na pintura. Outros problemas citados envolviam a colocação dos forros de gesso, a ausência de bancadas, louças e demais acessórios e problemas hidrossanitários (vazamentos nas torneiras e entupimento das tubulações). Já nas áreas comuns dos edifícios, foram citados no ato da entrega problemas hidrossanitários (vazamentos e entupimentos), infiltrações (principalmente em drenos de ar condicionado), falhas no acabamento das placas de gesso, ausência de sinalização e defeitos em diversos acessórios e equipamentos (caixas postais, portões, sensores de presença para iluminação etc.).

Após a entrega, foram detectadas manifestações patológicas nos apartamentos em $80 \%$ da amostra. Dentre os problemas mais citados, estão infiltrações, problemas no sistema elétrico e no sistema hidrossanitário.

Já em áreas comuns, foram encontrados problemas em todos os edifícios. As patologias mais citadas são infiltrações, problemas no sistema hidrossanitário e fissuras em alvenaria.

\subsection{Assistência Técnica.}

De acordo com as respostas do questionário, todos edificios da amostra são administrados por síndico junto à empresa especializada. Isso mostra uma maior preocupação dos proprietários com a gestão condominial, distribuindo as funções burocráticas da administração do edifício.

Todas as construtoras possuem um canal de atendimento para reclamações e pedidos de assistência técnica. Segundo as respostas do questionário, duas construtoras não forneceram todos os contatos de fornecedores e responsáveis técnicos, dificultando o acesso ao suporte completo ao condomínio. 0 síndico do Edifício 3 relatou dificuldades para entrar em contato com os projetistas do edifício para consultá-los sobre uma reforma na laje do reservatório de água superior.

Os síndicos e administradores relataram conhecer os prazos de garantia da edificação e seus sistemas, porém 40\% alegaram não saber dos requisitos para a perda dessa garantia, presentes nos Manuais de Uso, Operação e Manutenção. Os síndicos dos Edifícios 2 e 3 disseram que não houve orientação por parte das construtoras quanto ao Manual ou quanto aos requisitos para perda da garantia.

Sobre os processos de manutenção da edificação, as respostas foram diversas. Quando perguntados se as manutenções são realizadas regularmente, apenas o síndico do Edifício 3 afirmou que o programa de manutenção era seguido em sua totalidade. Para os administradores dos Edifícios 1 e 2, a maioria dos processos de manutenção são realizados periodicamente. No Edifício 4, apenas a minoria das manutenções previstas é feita. 
Já no Edifício 5, o programa de manutenção ainda estava em processo de elaboração. Por mais que seja o edifício mais novo dentre os que compõem a amostra (9 meses), o programa de manutenção já deveria estar pronto, tendo como base o modelo apresentado por sua construtora no Manual do Proprietário.

Ao questionar se os problemas encontrados na vistoria de entrega do edifício, foram integralmente resolvidos, $60 \%$ dos síndicos e administradores de condomínios responderam que sim, 20\% disseram que não e os demais $20 \%$ reforçaram que não encontraram defeitos ou falhas no ato da entrega do imóvel.

O cenário é mais grave para os problemas encontrados após o período de entrega do edifício, com destaque para dois casos. Mesmo acionando as construtoras dezenas de vezes, os Edifícios 1 e 3 possuem suportes deficitários. No restante dos edifícios da amostra, o suporte se mostrou eficiente até o presente momento.

A Construtora 1, responsável pelo Edifício 1, entrou em processo de falência há cerca de 1 ano e 8 meses. Segundo o síndico, a construtora cumpriu com suas obrigações durante a sua existência, mas o suporte foi descontinuado desde que a construtora encerrou suas atividades.

No caso do Edifício 3, existem problemas verificados na época da entrega (dezembro de 2018) e que ainda não foram resolvidos, principalmente dentro dos apartamentos. Segundo o síndico do edifício, a Construtora 3 passa por dificuldades financeiras e fez um acordo com os proprietários para que eles arcassem com os reparos e aguardassem o reembolso da construtora.

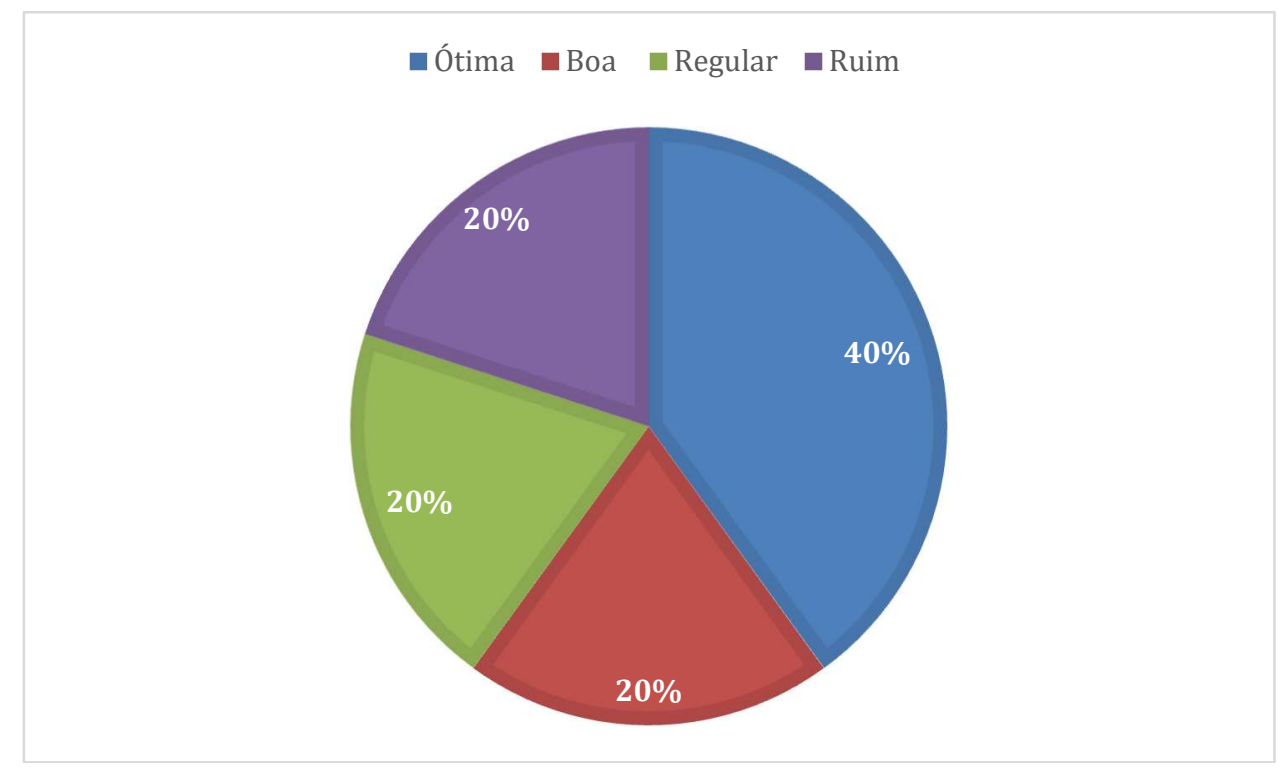

Figura 1-Gráfico referente assistência técnica da construtora pós entrega

A Figura 1 mostra graficamente as respostas dos síndicos e administradores dos condomínios quando questionados sobre a assistência técnica oferecida pela construtora, que trata da avaliação ao suporte das construtoras aos edifícios após a entrega da obra.

Apenas uma das cinco construtoras da amostra foram acionadas na Justiça para reparação dos danos. Segundo o síndico do Edifício 3, diversos proprietários ganharam o direito ao reparo dos danos em suas unidades após a decisão dos processos. 0 síndico do Edifício 2 relatou que alguns proprietários ameaçaram 
processar a Construtora 2, mas conseguiram ter suas demandas atendidas mediante acordos na esfera extrajudicial.

\section{Conclusões}

Com base nos resultados obtidos com as respostas do questionário, nota-se que algumas das construtoras responsáveis pelos edifícios da amostra não oferecem um suporte técnico completo aos edifícios. $A$ assistência técnica é tratada como algo secundário, de pouca importância pelas empresas, apesar de ser assegurado em contrato e por lei.

Duas das construtoras presentes no estudo estiveram em dificuldades financeiras, o que prejudicou o atendimento das demandas dos proprietários. As Construtoras 2 e 3 estiveram sob ameaças de processos judiciais; uma delas chegou a ser notificada judicialmente. Ambas atenderam aos pedidos dos moradores dos edifícios, mas apenas após a possibilidade de serem processadas. Atitudes como as citadas mostram que as empresas demostram menosprezo à etapa pós obra e não a consideram como parte importante do investimento necessário para construir uma edificação.

\section{Agradecimentos}

Á UFPB pelo suporte técnico e as empresas participantes da pesquisa.

\section{Referências Bibliográficas}

JESUS, A. et al. Comportamento Histórico no Brasil da Indústria da Construção Civil e suas Atuais Perspectivas. Revista Científica Multidisciplinar Núcleo do Conhecimento, n. 7, p. 87-95, 2018.

ASSOCIAÇÃO BRASILEIRA DE NORMAS TÉCNICAS. ABNT NBR 15575-1: Edificações habitacionais Desempenho - Parte 1: Requisitos gerais. ABNT. Rio de Janeiro. 2013.

ASSOCIAÇÃO BRASILEIRA DE NORMAS TÉCNICAS. ABNT 14037 - Diretrizes para elaboração de manuais de uso, operação e manutenção das edificações - Requisitos para elaboração e apresentação dos conteúdos. ABNT. Rio de Janeiro. 2014.

INSTITUTO BRASILEIRO DE AVALIAÇÕES E PERÍCIAS DE ENGENHARIA. Inspeção Predial - "A Saúde dos Edifícios". 2a. ed. São Paulo: [s.n.], 2015. 